Author version: J. Mar. Syst., vol.87(1); 2011; 47-54

\title{
Superimposition of wind seas on pre-existing swells off Goa coast
}

\author{
P. Vethamony ${ }^{* 1}$, V.M. Aboobacker ${ }^{1}$, H.B. Menon ${ }^{2}$, K. Ashok Kumar $^{1}$, L. Cavaleri ${ }^{3}$
}

1. National Institute of Oceanography, Dona Paula, Goa -403 004, India

2. Department of Marine Science, Goa University, Taleigao Plateau, Goa -403 206, India

3. Institute of Marine Sciences - CNR, Castello 1364/A, 30122 Venice, Italy

* Corresponding author: Ponnumony Vethamony, email: mony@nio.org, Ph: +91 832 2450473, Fax: Ph: +91 8322450608.

Associate authors: Aboobacker Valliyil Mohammed, email: vmabacker@gmail.com

Harilal B. Menon, email: hbmenon@unigoa.ac.in

K. Ashok Kumar, email: akumar@nio.org

Luigi Cavaleri, email: luigi.cavaleri@ismar.cnr.it

\begin{abstract}
An analysis of wind and wave data collected in the coastal region of Goa, west coast of India, during fair weather season reveals a distinct and systematic diurnal variation in wind speed, wave height and wave period, especially simultaneous increase in wave height and decrease in wave period with increase in local wind speeds due to sea breeze system. During a typical daily cycle, the wave height reaches its peak early in the afternoon, then it decays progressively back to the swell conditions within 5 or 6 hours. Measured wave spectra distinctly bring out salient features of deep water swell and wind seas generated by the local sea breeze. Numerical simulations reproduce the characteristics of this daily cycle. The exposure of Goa coast to long distant swells from the southwest and to the local wind seas from the northwest leads to complex cross-sea conditions.
\end{abstract}

Keywords: wind waves; sea breeze; swell; wave spectra; pre-monsoon; diurnal variations.

Regional index terms: Arabian Sea; west coast of India; off Goa. 


\section{Introduction}

The sea breeze circulation system - a common mesoscale meteorological phenomenon - has a profound effect on the meteorology and oceanography of coastal areas (Simpson, 1994). Sea breeze can create a highly dynamic environment in the nearshore regions, and beaches may respond rapidly to the changing wind wave climate. Several studies have been carried out on the wave characteristics due to sea breeze. The coastal region of Sydney, Australia, has been studied by, e.g,, Linacre and Hobbs (1977); Short and Trenaman (1992) and Masselink and Pattiaratchi (1998). During the summer season (October - April) they observed that the sea breeze is most prevalent between 12 and $21 \mathrm{~h}$ (local time), and typically produces $1-1.5 \mathrm{~m}$ high waves with periods ranging between 6 and $9 \mathrm{~s}$. Masselink and Pattiaratchi (1998) pointed out that following the onset of sea breeze, addition of locally generated wind waves to background swell resulted in an increase in wave height and a decrease in mean wave period. Verhagen and Savov (1999) studied wave growth due to sea breeze in Cartagena (Colombia) region, and estimated the duration of wave action based on that of the sea breeze.

Goa is located on the west coast of India (Figure 1), and it extends $125 \mathrm{~km}$ in the north-south direction. It has been observed for a long time that the calm sea off Goa during fair weather season becomes more rough in the afternoon hours. There were incidents of boat capsizing even during fair weather season (March 2004). Shipping Corporation of India has initiated a program for the Goa coast, where the Mormugao Port Trust is situated, to fix an Inland Vessel Limit (IVL) for the movement of vessels such as barges and boats based on a maximum wave height of $2 \mathrm{~m}$. In this context, a pilot study was carried out by Vethamony et al (2009) to find out the safety of inland vessels operating in the Mormugao port region based on the distribution of significant wave heights. The analysis of the data (measured wave parameters and wave spectra) used for the above project reveals diurnal variations (due to co-existence of locally generated wind seas over the pre-existing swells). However, the related effects cannot be generalized at all the coastal locations of India. For instance, Aboobacker et al (2009) studied the spectral wave characteristics off Paradip, on the east coast of India, based on measured waves during an eight month period. They could not find variations as found in the Goa region. This is likely to depend both on the characteristics of the local area (land features and sea temperature leading to sea breeze) and on the easterly exposure to the dominant swells.

One of the difficulties in studying the action of the sea breeze waves is the lack of sufficient knowledge of their spatial distribution. In this respect, valuable information is provided by scatterometer. The SeaWinds scatterometer onboard QuikSCAT provide instantaneous wind vectors along a wide swath (1800 km) (Ebuchi et al., 2002). Gille et al. (2003) used QuikSCAT data to study the 
characteristics of sea breeze and land breeze systems present in most of the world's coastlines. Aparna et al. (2005) studied the seaward extension of the sea breeze along the southwest coast of India utilizing QuikSCAT winds.

For this study, we do not have high resolution winds capable of resolving the fine details of the sea breeze. This is a rather common situation along most of the world coasts. Our main purpose is to explore how far we could go using freely available information, such as the NCEP wind fields. These winds have been used by Vethamony et al. (2006) to simulate waves in the north Indian Ocean, and the modelled wave parameters match reasonably well with measurements. The present study aims at (i) understanding the diurnal variation of wave parameters along and off the coast of the Goa region and (ii) studying the impact of sea breeze on the local wave climate. The wind data used includes sources such as the Autonomous Weather Station (AWS) of NIO (National Institute of Oceanography, Goa, India), QuikSCAT data (Tang and Liu, 1996) and the wind fields available from NCEP (National Centers for Environmental Predictions, USA) (Kalney et al., 1996). Verification data used for the validation of the wave model results includes the wave parameters obtained from field measurements (using Directional wave rider buoys) and from Jason-1, a relatively small satellite developed by NASA (National Aeronautics and Space Administration, USA) and CNES (Centre National d'Etudes Spatiales, France), and designed for oceanographic and meteorological purposes.

The paper is organized as follows; Section 2 provides a compact description of the area of interest. Section 3 lists the available model (input) and measured data. In section 4, we describe the methodology used for the study, while the results are shown and discussed in Section 5. We draw our conclusions in the final Section 6.

\section{The area of interest}

Figure 1 shows the study area including the wind and wave measurement locations and the Indian Ocean region (inset). The coastal region of Goa is characterized by three different seasons, premonsoon (February - May), southwest monsoon (June - September) and post-monsoon (October January). During fair weather season (post-monsoon and pre-monsoon seasons), the sea is relatively calm. Waves off the Goa coast during the southwest monsoon season are predominantly swells, whose periods range between 8 and $10 \mathrm{~s}$ (Sanil Kumar et al., 2000). Swells from the south Indian

Ocean and the Arabian Sea are always present in the coastal region off Goa, stronger during southwest monsoon season and weaker during pre-monsoon and post-monsoon seasons (Shahul 
Hameed et al., 2007). During pre-monsoon season, the daily cycle of sea conditions near the Goa coast is influenced by sea breeze (Neetu et al., 2006).

(Figure 1)

Mormugao Port, a major port of India, is situated on the Goa coast. The Mormugao Port is protected by a breakwater, and to the north of Mormugao Bay, stretches of sandy and rocky coasts are found. During southwest monsoon season, inland vessels are not operational.

\section{Data used}

For validation of the wave model results, we have used the wave data collected (by Datawell directional wave rider buoys) at two shallow water locations off Goa (water depth = $20 \mathrm{~m}$ and $15 \mathrm{~m}$ ) during the periods 01 - 21 May 2005 and 06 - 20 May 2005, respectively (see Figure 1 for their locations). Waves were measured for every $1 \mathrm{~h}$ with a sampling period of 20 minutes. The buoy can function within -20 to +20 m of wave height with an accuracy of $3 \%$ within the wave period of 1.6 to 30 s. The direction accuracy is within 0.5 to $2^{\circ}$ depending on the latitude. Simultaneous wind measurements with a sampling period of 10 minutes were carried out at $43.5 \mathrm{~m}$ height using the Autonomous Weather Station (AWS) located at Dona Paula. The accuracy of wind measurements: \pm 0.3 $\mathrm{m} / \mathrm{s}$ for speed and $\pm 3^{\circ}$ for direction. The measured wind is reduced at $10 \mathrm{~m}$ height a using logarithmic wind profile,

$$
\mathrm{U}(\mathrm{z})=\frac{\mathrm{u}_{\mathrm{q}}}{\mathrm{K}} \ln \left(\mathrm{z} / \mathrm{z}_{0}\right)
$$

where $\mathrm{U}(\mathrm{z})$ is the wind speed measured at a height, $\mathrm{Z}(=43.5 \mathrm{~m}), \mathrm{U}_{\mathrm{s}}$ the surface friction velocity, $\mathrm{Z}_{0}$ $(=0.22 \mathrm{~m})$ the aerodynamic roughness length (the AWS is situated on top of the NIO building approximately $300 \mathrm{~m}$ away from the sea and the area is surrounded by low lying trees) and $\mathrm{k}(=0.4)$ is the von Karman constant.

Wind vectors of these reduced winds are plotted on a daily basis for direct inspection. One example is in (Figure 2 (a)). The vector arrow indicates the wind is 'blowing to'.

(Figure 2) 
Concerning remote sensing and model data, QuikSCAT vector winds with $0.5^{\circ} \times 0.5^{\circ}$ resolution available twice daily (06 $\mathrm{h}$ and $18 \mathrm{~h}$, local time) (Tang and Liu, 1996) have been used to analyze the open ocean as well as coastal wind variations (Figure 3). Reanalysis wind vectors from NCEP, NOAA (National Oceanic and Atmospheric Administration, USA), at six-hourly intervals and $2.5^{\circ} \times 2.5^{\circ}$ grid resolutions (Kalney et al, 1996), have been used to study wind variations in deep waters. Alternate 3 and 4 days gridded $\left(1^{\circ} \times 1^{\circ}\right.$ resolution) mean significant wave heights from Jason- 1 are also utilized in this study (Quilfen et al, 2004). As the Jason-1 altimeter provides only two data points (one pass every ten days) for the study area during the period of interest, obviously insufficient for a useful comparison, we have considered gridded altimeter data. While the gridded data cannot be used for model validation, they do provide useful information on general quality of the wave model results.

(Figure 3)

\section{Methodology}

Wave simulations were carried out over two domains - regional and local (Figures $4 \mathrm{a}$ and $4 \mathrm{~b}$ ): the Indian Ocean region $\left(30^{\circ} \mathrm{S}-30^{\circ} \mathrm{N}, 35^{\circ}-115^{\circ} \mathrm{E}\right)$ and off Goa region $\left(13^{\circ} 09^{\prime}-18^{\circ} 18^{\prime} \mathrm{N}, 70^{\circ} 06^{\prime}\right.$ - 74 45’ E) utilizing MIKE 21 Spectral Wave model (SW) (DHI, 2007) with NCEP winds. The flexible mesh bathymetries were generated using ETOPO5 data obtained from NGDC (National Geophysical Data Centre, Colorado, USA) for offshore regions and C-MAP electronic chart database of MIKE 21 for nearshore regions. The triangulated mesh sizes are $1.5^{\circ}$ in the south Indian Ocean, $0.75^{\circ}$ in the north Indian Ocean, $0.25^{\circ}$ along the Indian coast, $15 \mathrm{~km}$ at the central west coast of India and $1 \mathrm{~km}$ off the Goa coast. The model is based on the wave action conservation equation (Komen et al., 1994 and Young, 1999), where the directional-frequency wave action spectrum is the dependent variable. Simulated parameters such as significant wave height $\left(H_{s}\right)$, mean wave period $\left(T_{m}\right)$ and mean wave direction $(\theta)$ were stored at $1 \mathrm{~h}$ interval.

(Figure 4)

The boundary conditions for the local domain were extracted from the output of the regional domain. The NCEP winds within the domain were applied as the input parameter. Since, the AWS winds were measured on the land (of course, close to the coast) and the magnitudes (especially uvelocity) are significantly low compared to the NCEP winds of the grid closest to the coast (Figure 5), the AWS winds were not used for wave simulations. However, they provide an indication to the 
variations in wind patterns associated with sea breeze - land breeze system prevailed over the region. The model wave parameters were validated with measurements.

(Figure 5)

\section{Results and discussion}

Winds from the AWS for the coastal region off Goa show nearly semi-diurnal variations both in their magnitude and direction (Figure 2). The prominent incoming directions are NW (from sea to land) and NE (from land to sea). The speeds are relatively higher for northwesterlies. The sea breeze and land breeze systems are nearly perpendicular to each other, the former roughly parallel and the latter perpendicular to the orientation of the Goa coast. Sea breeze starts around $11 \mathrm{~h}$, and continues to blow in the NW direction with maximum wind speed between $15 \mathrm{~h}$ and $18 \mathrm{~h}$, and then it gradually reduces its speed. Very early in the morning, the wind shifts its direction to NE (land to sea) and continues till 11h, with drastically reduced speeds compared to sea breeze. These variations are found to be systematic throughout the study period, and consistent with the results of earlier studies (e.g., Masselink and Pattiaratchi, 1998). Aparna et al. (2005) showed that the sea breeze-land breeze systems are prominent in this region during the pre-monsoon season. In general, the highest wind speeds are observed around $15 \mathrm{~h}$ and the lowest around 06h. The maximum wind speed observed during the period of study in May 2005 was $4.6 \mathrm{~m} / \mathrm{s}$ from the NW direction. On several occasions no wind is observed in the early hours of the day.

The sea-land breeze system leads to a typical cycle of local waves (Figure 2b). Following the onset of sea breeze, a wind wave system grows in time, following the progressive extension of the sea breeze area towards offshore. While, once begun, the wind speed present close to the coast remains relatively constant, the consequent increase of fetch with respect to the coastal area leads to an increase of the derived wave height (Figure 2 and Figure 6). Although relatively limited, the increase of $H_{s}$ shows that the local wind sea has energy comparable to or larger than the permanent background swell.

\section{(Figure 6)}

The time evolution of the sea breeze implies a time lag between the onset of the sea breeze and the maximum wave conditions reached at the coast. Interestingly, the local experience has led to a practical rule used by the local mariners, indicating that the maximum $H_{s}$ is reached between 3 and 4 
hours after the sea breeze begins, as seen clearly also in the local measurements (Figure 6). Combined with the wave generation rules (see, e.g., SWAMP group, 1985), this suggests a substantial offshore extension of the area, which is affected by the sea breeze. Although relatively strong, this local sea breeze is only crudely visible in the NCEP wind fields, whose resolution is by far too crude to describe it in sufficient detail. In this respect, better information is provided by the QuikSCAT winds, which provide an idea of the offshore area affected by the sea breeze.

Aparna et al (2005) suggest that the offshore extension of the sea breeze can be upto $180 \mathrm{~km}$. The QuikSCAT data suggests a lower figure for offshore distance. The wind distribution in Figure $3 \mathrm{~b}$ shows that when the five points (Q1 to Q5) give more or less the same value (before $3^{\text {rd }}$ and after $13^{\text {th }}$ May), the situation is dominated by some large scale feature. On the contrary, we find that between $3^{\text {rd }}$ and $13^{\text {th }}$ May, wind speed increases towards the coast (for e.g., at Q4 and Q5). This suggests that at least at the time of the QuikSCAT passes, i.e. at 18 UTC, the offshore extension of the sea breeze area was between 70 and $120 \mathrm{~km}$ (i.e. between Q4 and Q5 positions).

An independent indication of the offshore extension where the sea breeze is strong enough to generate waves is derived from the decay of the wave conditions. During a typical daily cycle, the wave height reaches its peak early in the afternoon, then it decays progressively back to the swell conditions within 5 or 6 hours. Given the typical sea breeze speed between 4 and $5 \mathrm{~m} / \mathrm{s}$, the wind sea has a $H_{s}$ (not the overall $H_{s}$ ) of the order of $0.5-0.6 \mathrm{~m}$. This is very close to the fully developed conditions (for the breeze speed) requiring a minimum fetch of $40-50 \mathrm{~km}$. This is not useful for our purpose as the area affected by the sea breeze is known to be larger. However, another consideration is possible. The typical peak period of sea breeze waves is between 3 and 4 s (Sanil Kumar et al., 2000), fully consistent with wind sea $H_{s}$ of 0.5 to $0.6 \mathrm{~m}$, and whose energy travels at about $10 \mathrm{~km} / \mathrm{h}$. So, the decay time plus the necessary fetch for the most offshore generation suggests an overall extension of the wave generation active zone between 70 and $80 \mathrm{~km}$, well beyond Q3 offshore (Figure 3)

(Figure 7)

Notwithstanding the limitations of the coarse wind, a first order understanding of the process can be provided by the wave model results obtained using large scale NCEP winds. Figure 7 shows a comparison between modelled and measured $H_{s}$ at the $20 \mathrm{~m}$ depth buoy. The gridded $H_{s}$ from Jason-1 also match with the modelling and measurements, even though they are averaged (both spatially and temporally). While there are local differences that we associate with the crude wind data (used as input 
to the wave model), results are consistent with the measured ones, as seen in the related scatter diagram shown in Figure $7 \mathrm{~b}$. The model wave parameters give correlation coefficients of $0.77,0.72$ and 0.63 for total, swell and wind sea heights, respectively with the measurements. The bias and r.m.s. error are marginal, and the scatter indices (S.I.) are 0.13, 0.16 and 0.24 for total, swell and wind sea heights, respectively. Swell $H_{s}$ follows nearly the same range (between 0.5 and $0.95 \mathrm{~m}$ ) during the study period, and as expected the wind sea $H_{s}$ follows diurnal variation according to the local sea breeze. The light wind seas generated (in the same direction of the swell) due to light winds could not be identified because of limitations in the resolution of wind data. Also, the swell $H_{s}$ are significantly low for a proper wind generation in the marine boundary layer.

Though the temporal scale of the coarse wind (NCEP) is larger, the simulated wave parameters match with the measurements. Hence, in regions, where fine resolution winds are not available we can use coarse winds as a first approximation to get reasonably good wave information.

(Figure 8)

Modelling provides a clear evidence of the daily cycle both in terms of $H_{s}$ and $T_{m}$. All this becomes clear when we analyze the measured spectra shown in Figure 8 and Figure 9 for 2D and 1D spectra, respectively. Figure 8 shows clearly, at 3-hour intervals, the onset of sea breeze waves around $300^{\circ}$ incoming direction, while the swell from $220^{\circ}-230^{\circ}$ are at much lower frequency, and permanently present. The energy associated with the two different wave systems, wind sea and swell, is derived immediately from Figure 9. The onset of sea breeze leads to a decrease of $T_{m}$. However, the two figures clearly show how representing the local situation only as $H_{s}$ and $T_{m}$, as seen in Figure 10, provides a very poor evidence of the truth. Also from the maritime safety point of view, the presence of cross-sea conditions (here represented by the SW swell and NW wind sea), is more difficult than a single wave system with the same overall wave height. These cross conditions are typical of the central and southern part of the west coast of India, because of its exposure to long distance swell from the SW direction.

(Figure 9)

(Figure 10) 
Clearly, a deeper quantitative analysis of the local generation requires higher resolution winds capable of resolving the details of the wind speed gradient when moving progressively from the Goa coast towards offshore. A more detailed input will allow us to attack another interesting problem. The present theories of wave generation embedded in the various spectral models (e.g., WAM, WAVEWATCH III, etc.) consider the input by wind to a given spectral component (specified in frequency and direction) as independent of energy present in other components. The process of energy transfer from wind to waves is based on a relationship between the wind speed close to the surface and the wave phase speed. However, in case of light winds (as is the case off Goa during pre-monsoon season), the presence of swells (please see Hogstrom et al. 2009, Semedo et al., 2009; Smedman et al., 2009) deeply modify the atmospheric marine boundary layer, reversing upwards the overall flux of momentum - long waves pump energy into the calm atmosphere. The question which is not yet completely clarified is whether a light wind can still produce light wind sea superimposed to swell in such conditions. The above studies carried out in the Baltic Sea suggest that this is indeed the case the overall upward flux of momentum being the sum of the upward flux due to swell and the downward flux associated with the light wind, the latter being connected to the local generation of light wind seas. This process has been frequently observed while measuring waves on an oceanographic tower in the Adriatic Sea. However, the present measurements do not contribute substantially to clarify this question, as the sea breeze and swells were not in the same direction.

\section{Conclusions}

Wave measurements and model simulations show that during the daily cycle deep water and coastal winds in front of Goa lead to the superimposition of locally generated waves from NW with the preexisting swell from SW. This leads to an obvious increase in wave height, while the superimposition of two wave systems with completely different dominant frequency ranges leads to a formal decrease of the mean wave period, previously coincident with the swell period. We purposely use the word 'formal' because the situation shows clearly the possible misleading use of this parameter, particularly in areas exposed to swell from various possible directions. This is perfectly shown by the directional wave energy spectra with the two systems, swell from SW and wind sea from NW, with completely different frequency and direction. The implications are not only formal. Although relatively mild, the cross sea conditions will have a considerable impact on the local maritime activities and harbour management. This clearly shows the need for a suitable local wave forecast system capable, granted sufficiently high resolution winds are available, not only of providing the basic wave integrated parameters $\left(H_{s}, T_{m}\right.$ and $\theta)$, but also a complete 2D spectral description of the expected conditions. 
A full 2D representation of the wave systems present on the coasts of Goa has strong implications also for the management of the many large beaches present along the local coastlines. The two local wave systems, swells and locally generated waves, will have quite different effects in restoring the beach morphology disrupted by the severe monsoon waves.

Notwithstanding these limitations, it is clear that a first order approximation to the actual sea conditions present in exposed areas subject to coastal breezes can be obtained on the basis of data publicly available. This may be useful for quick assessment of the conditions present where no data are immediately available. A more scientifically relevant problem is the use of the local conditions to study the influence of swell on the local wind generation. This work is in progress and will be reported in due time.

\section{Acknowledgments}

We thank Dr. S.R. Shetye, Director, National Institute of Oceanography (NIO), Goa, for his interest in this study and our colleagues, especially Mr. P.S. Pednekar, for their involvement in data collection. The NIO contribution number is $x x x x$.

\section{References}

Aboobacker, V.M., Vethamony, P., Sudheesh, K., Rupali, S.P., 2009. Spectral characteristics of the nearshore waves off Paradip, India during monsoon and extreme events. Natural Hazards, 49, 311323.

Aparna, M., Shetye, S.R., Shankar, D., Shenoi, S.S.C., Mehra, P., Desai, R.G.P., 2005. Estimating the seaward extent of sea breeze from QuikSCAT scatterometry. Geophys. Res. Lett., 32, L13601, doi,10.1029/2005GL023107.

Danish Hydraulic Institute (DHI), 2001. User manual and reference guide for MIKE 21, DHI, Horsholm, Denmark.

Ebuchi, N., Graber, H.C., Caruso, M.J., 2002. Evaluation of wind vectors observed by QuikSCAT/SeaWinds using ocean buoy data. Journal of Atmospheric and Oceanic Technology, 19, 2049-2062.

Gille, S. T., Llewellyn Smith, S.G., Lee, S.M., 2003. Measuring the sea breeze from QuikSCAT Scatterometry. Geophysical Research Letters, 30(3), 1114, doi, 10.1029/2002GL016230.

Hogstrom, U., Smedman, A., Sahlee, E., Drennan, W.M., Kahma, K.K., Pettersson, H., Zhang, F., 2009. The atmospheric boundary layer during swell: a field study and interpretations of the turbulent kinetic energy budget for high wave ages, Journal of the Atmospheric Sciences, 66, 2764-2779.

Kalnay, E., Kanamitsu, R. Kistler, Collins, W., Deaven, D., Gandin, L., Iredell, M., Saha, S., White, G., Woollen, J., Zhu, Y., Chelliah, M., Ebsuzaki, W., Higgins, W., Janowiak, J., Mo, K.C., Ropelewski, C., Wang, J., Leetma, A., Reynolds, R., Jenne, R., Joseph, D., 1996. The NCEP/NCAR 40-Year Reanalysis Project. Bull. Amer. meteor. Soc., 77, 437 - 471. 
Komen, G.J., Cavaleri, L., Donelan, M., Hasselmann, K., Hasselmann, S., Janssen, P.A.E.M., 1994. Dynamics and Modelling of Ocean Waves. Cambridge University Press, Cambridge, 532 pp.

Linacre, E., Hobbs, J., 1977. 'The Australian Climatic Environment.' 354 pp. (John Wiley \& Sons, Brisbane.).

Masselink Gerhard, Charithra B. Pattiarchi, 1998. The effect of sea breeze on beach morphology, surf zone hydrodynamics and sediment resuspension. Marine Geology, 146, 115-135.

Neetu, S., Satish Shetye, Chandramohan, P., 2006. Impact of sea-breeze on wind-seas off Goa, west coast of India. Journal of Earth System Science, 115(2), 229-234.

Quilfen Y., Chapron, B., Collard, F., Serre, M., 2004. Calibration/Validation of an altimeter wave period model and application to TOPEX/Poseidon and Jason-1 altimeters. Marine Geodesy, 27, 3-4, 511-534.

Sanil Kumar, V., Ashok Kumar, K., Anand, N.M., 2000. Characteristics of waves off Goa, west coast of India. Journal of Coastal Research, 16(3), 782-789.

Semedo, A., Saetra, O., Rutgersson, A., Kahma, K.K., Pettersson, H., 2009. Wave-induced wind in the marine boundary layer, Journal of the Atmospheric Sciences, 66, 2256-2271.

Shahul Hameed, T.S., Kurian, N.P., Thomas, K.V., Rajith, K., Prakash, T.N., 2007. Wave and current regime off the southwest coast of India, Journal of Coastal Research 23(5), 1167-1174.

Short, A. D., Trenaman, N.L., 1992. Wave Climate of the Sydney Region, an Energetic and Highly Variable Ocean Wave Regime. Aust. J. Mar. Freshwater Res., 43, 765-91.

Simpson, J.E., 1994. Sea-breeze and local winds. Cambridge University Press, New York, 234 p.

Smedman, A., Hogstrom, U., Sahlee, E., Drennan, W.M., Kahma, K.K., Pettersson, H., Zhang, F., 2009. Observational study of marine atmospheric boundary layer characteristics during swell, Journal of the Atmospheric Sciences, 66, 2747-2763.

SWAMP Group, 1985. An inter-comparison study of wind wave prediction models. Part I, Principal results and conclusions. In, Ocean Wave Modelling, Plenum Press, New York, 256 pp.

Tang, W., Liu, W.T., 1996. Objective interpolation of scatterometer winds. JPL publication, 96, 19. 16pp.

Verhagen, H.J., Savov, B., 1999. Sea breeze generated waves and Coastal Morphology; in, proc. Int. Medcoast conference on Wind and Waves, Antalya, Turkey, 28, 349-360.

Vethamony P., Aboobacker, V.M., Sudheesh, K., Babu, MT., Ashok Kumar, K., 2009. Demarcation of inland vessels' limit off Mormugao Port region, India, a pilot study for the safety for inland vessels using wave modelling. Natural Hazards, 49, 411-420.

Vethamony, P., Sudheesh, K., Rupali, S.P., Babu, M.T., Jayakumar, S., Saran, A.K., Basu, S.K., Raj Kumar, Abhijit Sarkar, 2006. Wave modelling for the north Indian Ocean using MSMR analysed winds. International Journal of Remote Sensing, 27, 18, 3767-3780.

WAMDI Group, 1988. The WAM model-A third generation ocean wave prediction model, J. Physi. Oceanography, 18, 1775-1810.

Young, I.R., 1999. Wind-generated ocean waves, In Elsevier Ocean Engineering Book Series, Volume 2. Eds. R. Bhattacharyya and M.E. McCormick, Elsevier. 


\section{Figure captions}

Figure $1 \quad$ Study area showing the locations of wind and wave measurements (AWS - Autonomous Weather Station; B1 and B2 - Wave rider buoy locations).

Figure 2 Measured (a) AWS wind distribution at Dona Paula (blowing to) and (b) significant wave height and mean wave period at $20 \mathrm{~m}$ water depth on 12 May 2005. See Figure 1 for the respective locations.

Figure 3 QuikSCAT winds off Goa, (a) locations from offshore to coast (Q1 to Q5) and (b) time series of the wind speed distribution at the locations Q1 to Q5 during part of May 2005. Satellite passes are at 06 and 18 UTC.

Figure $4 \quad$ Flexible mesh bathymetries used for the wave simulations: (a) Regional domain and (b) local domain.

Figure 5 Comparison between measured (AWS) and NCEP wind vectors: (a) u-velocity and (b) vvelocity.

Figure 6 Distribution of measured (a) AWS winds at Dona Paula coastal station, (b) Significant wave height at $20 \mathrm{~m}$ and $15 \mathrm{~m}$ water depths and (c) Mean wave period at $20 \mathrm{~m}$ and $15 \mathrm{~m}$ water depths. See Figure 1 for the respective locations.

Figure 7 Distribution of significant wave heights during 1-21 May 2005 at $20 \mathrm{~m}$ depth location: (a) comparison between measured and modelled total, swell and wind sea $H_{s}$ and (b) scatter between measured and modelled total, swell and wind sea $H_{s}$.

Figure $8 \quad$ Measured directional energy spectra from 00h to 21h (for every 3 hour) on 19 May 2005.

Figure $9 \quad$ Typical 1D spectra measured on 09 May 2005.

Figure 10 Distributions of modelled significant wave height and mean wave period during May 2005 extracted for the location at 20m depth, showing an inverse proportion in its variations. 


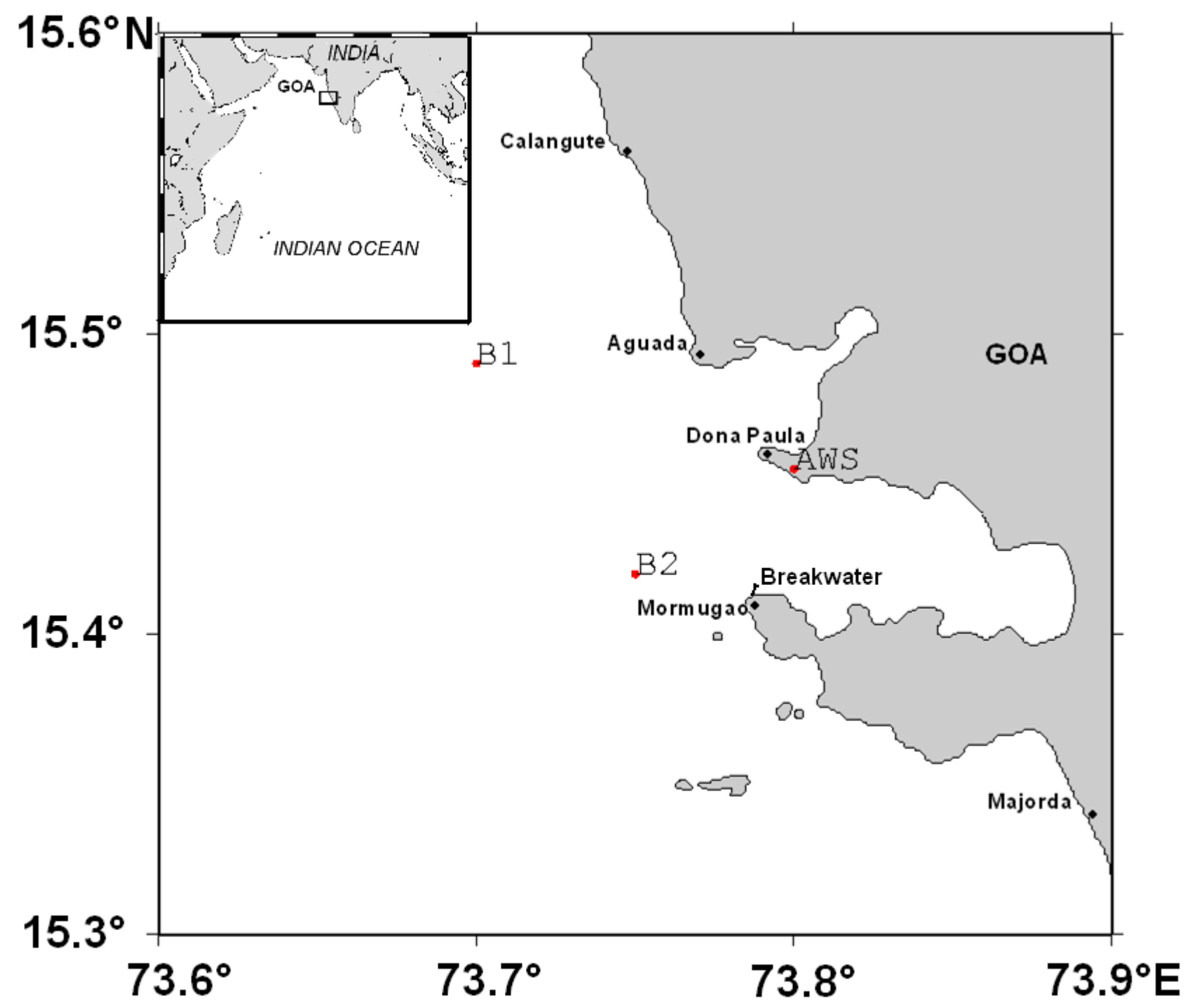

Figure 1 
(a)
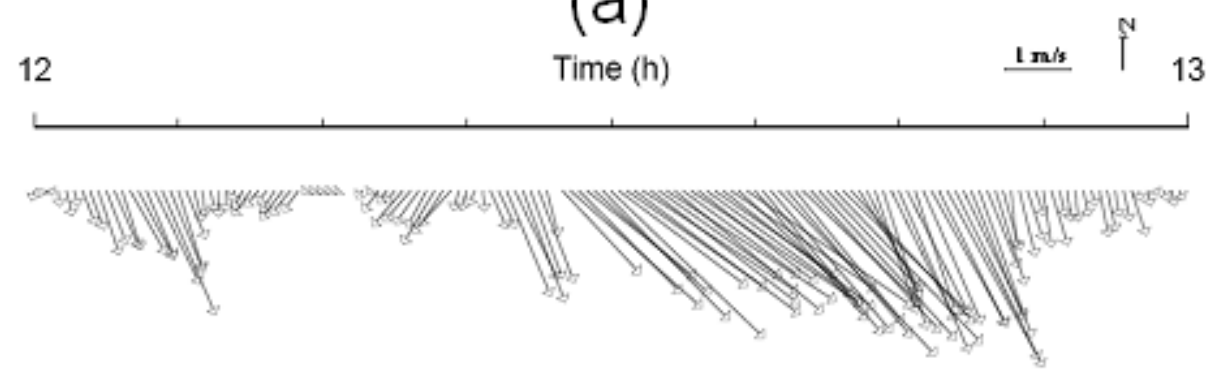

(b)

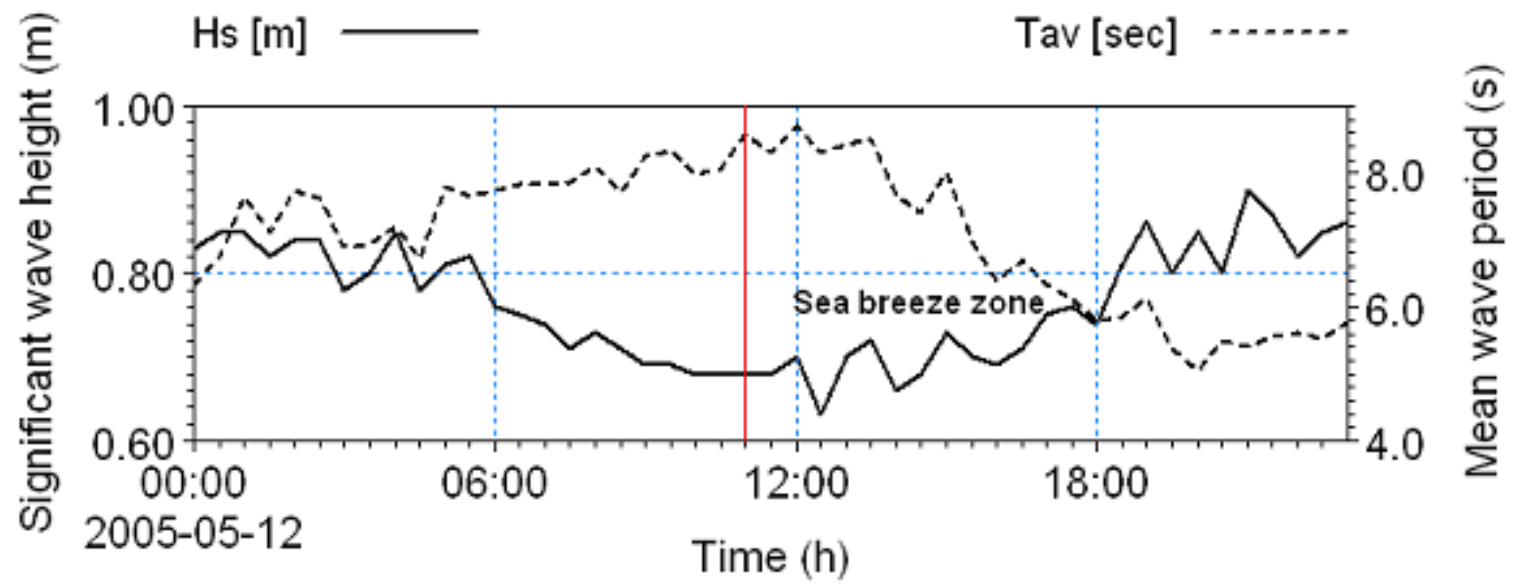

Figure 2 
(a)

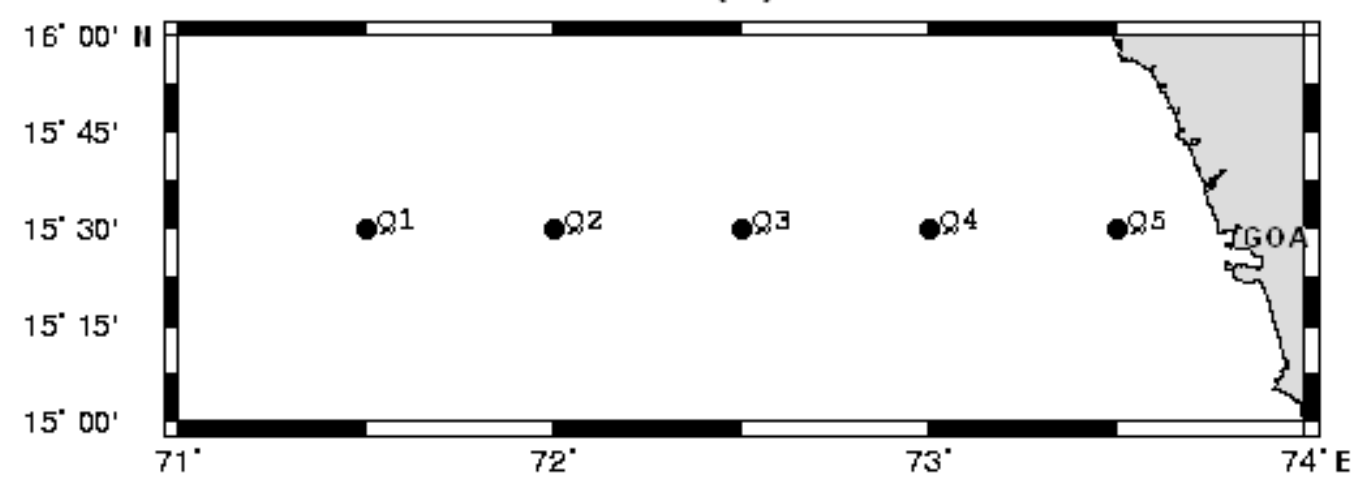

(b)

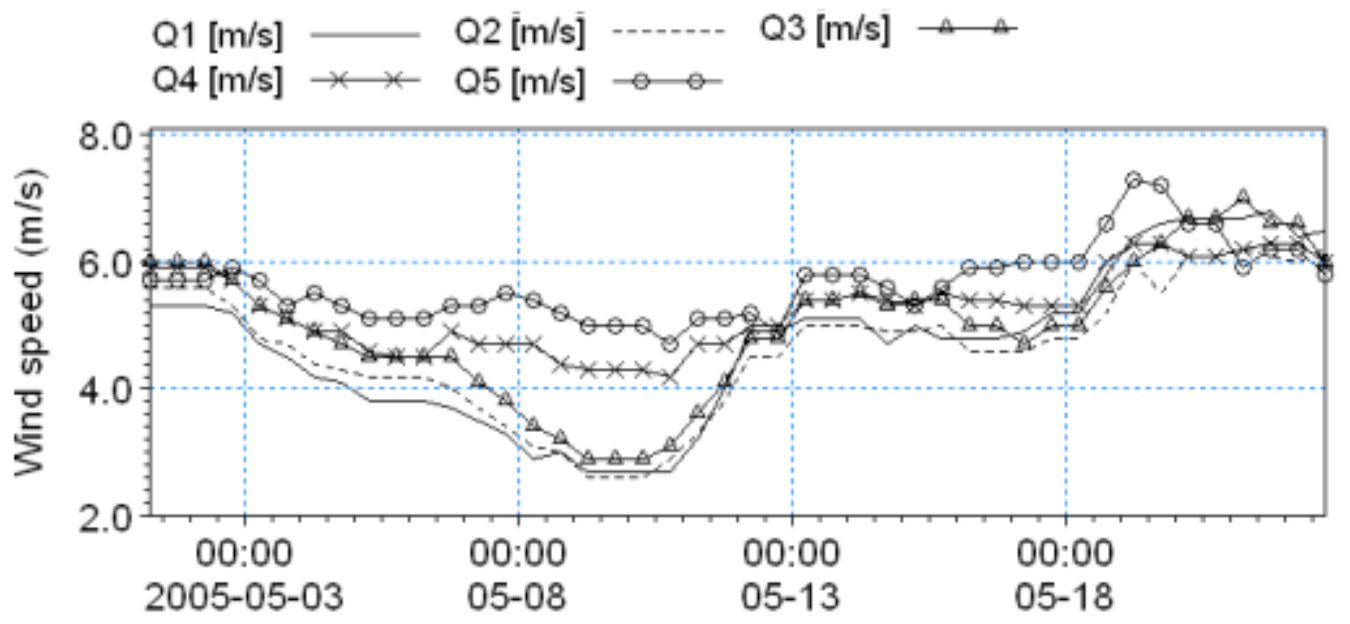

Figure 3 
(a)
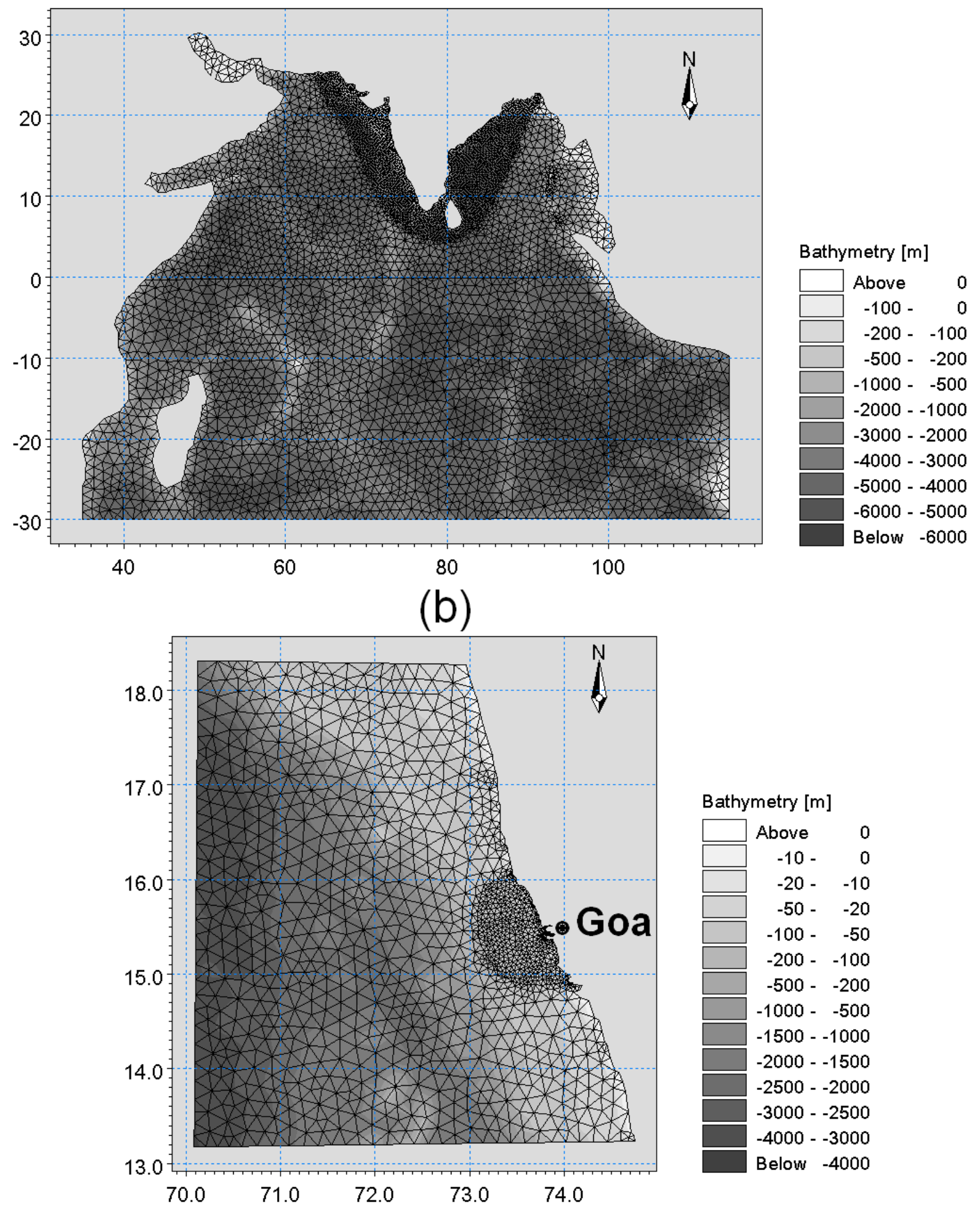

Figure 4 


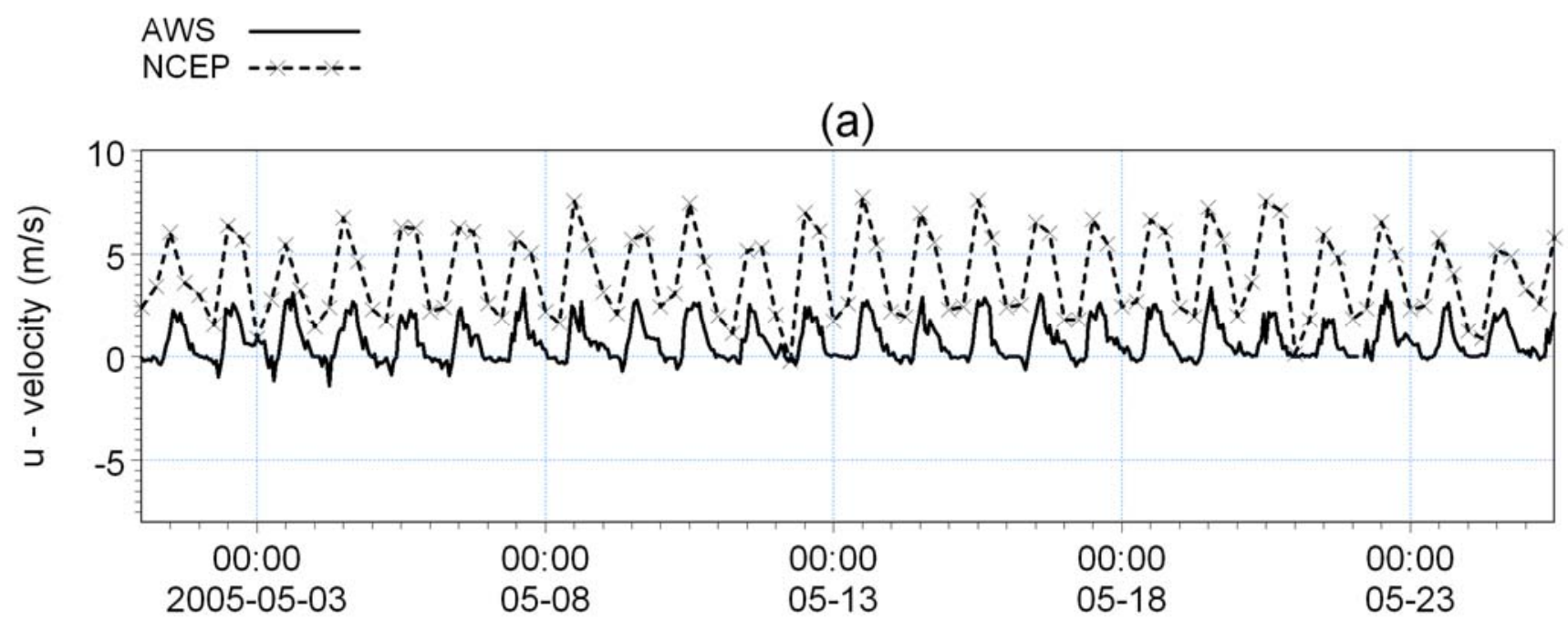

(b)

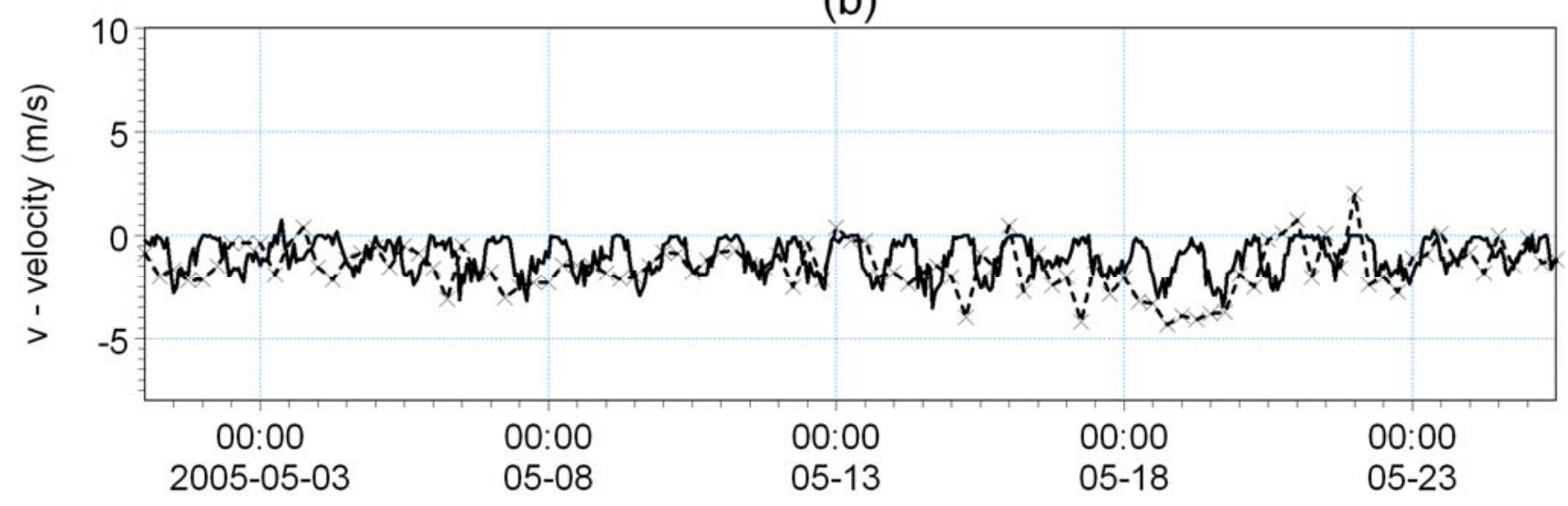

Figure 5 
(a)

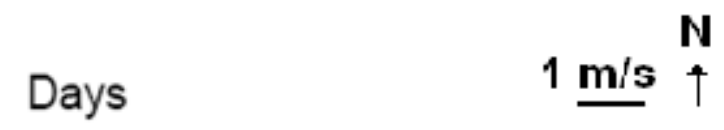

$\begin{array}{llllllllllllllllllllll}1 & 2 & 3 & 4 & 5 & 6 & 7 & 8 & 9 & 10 & 11 & 12 & 13 & 14 & 15 & 16 & 17 & 18 & 19 & 20 & 21 & 22\end{array}$

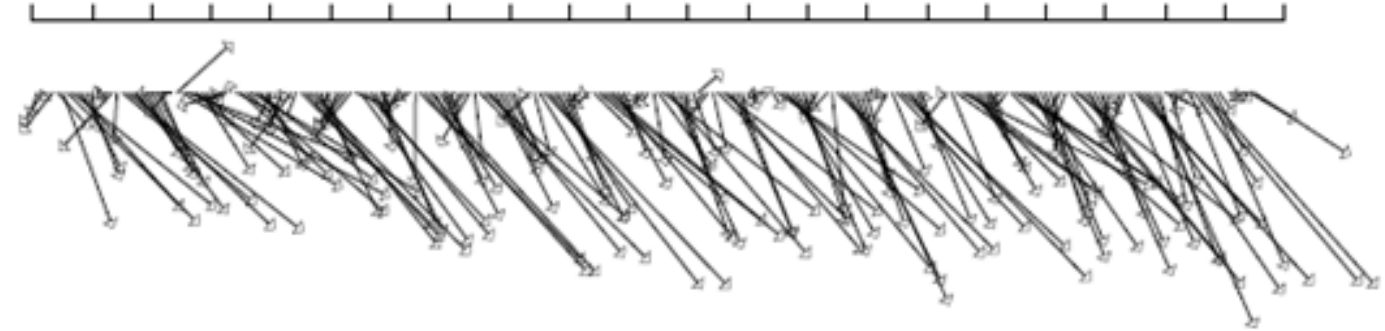

(b)

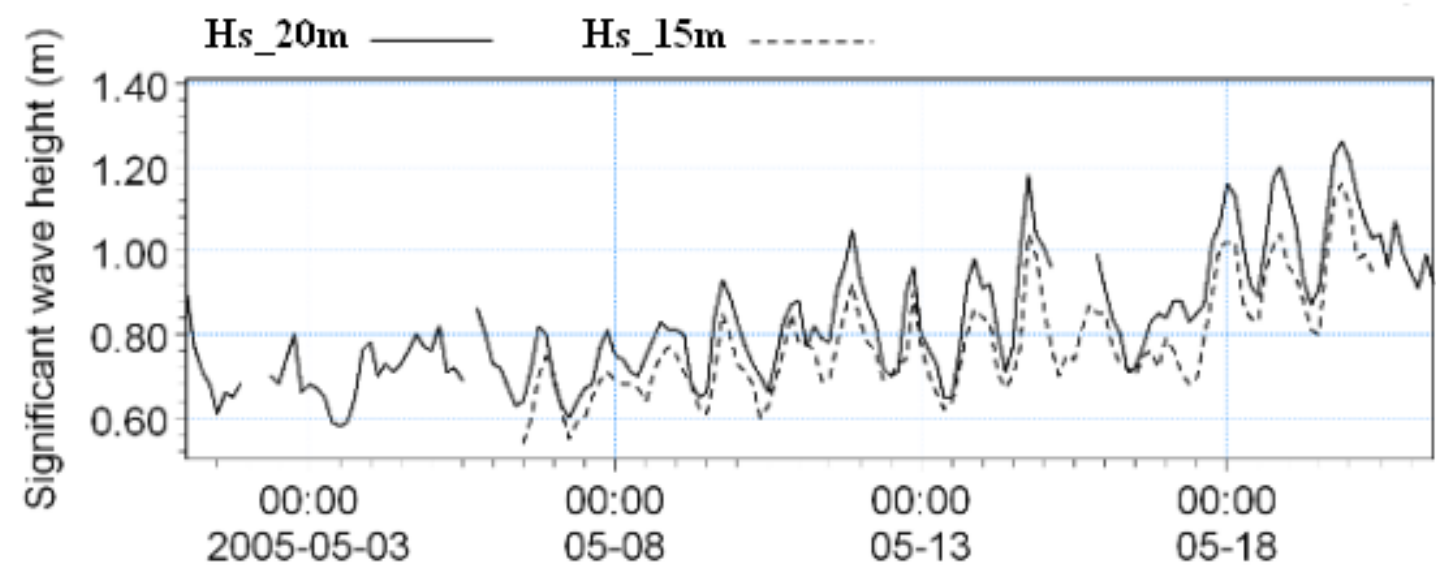

(c)

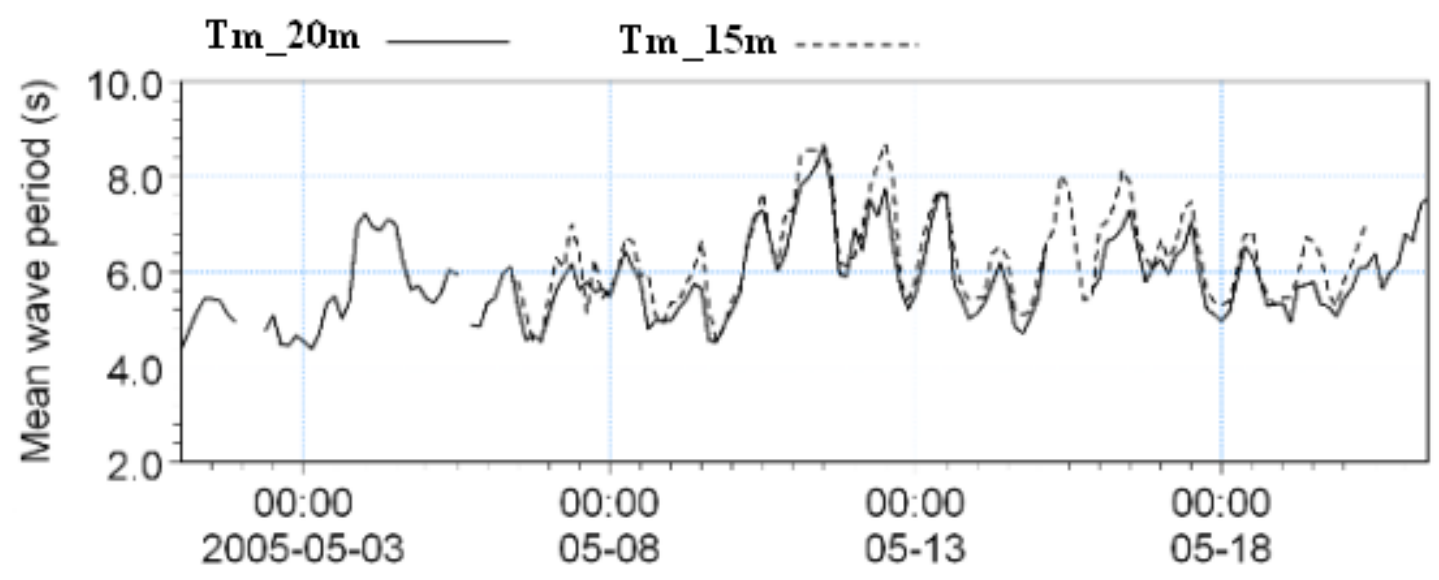

Figure 6 

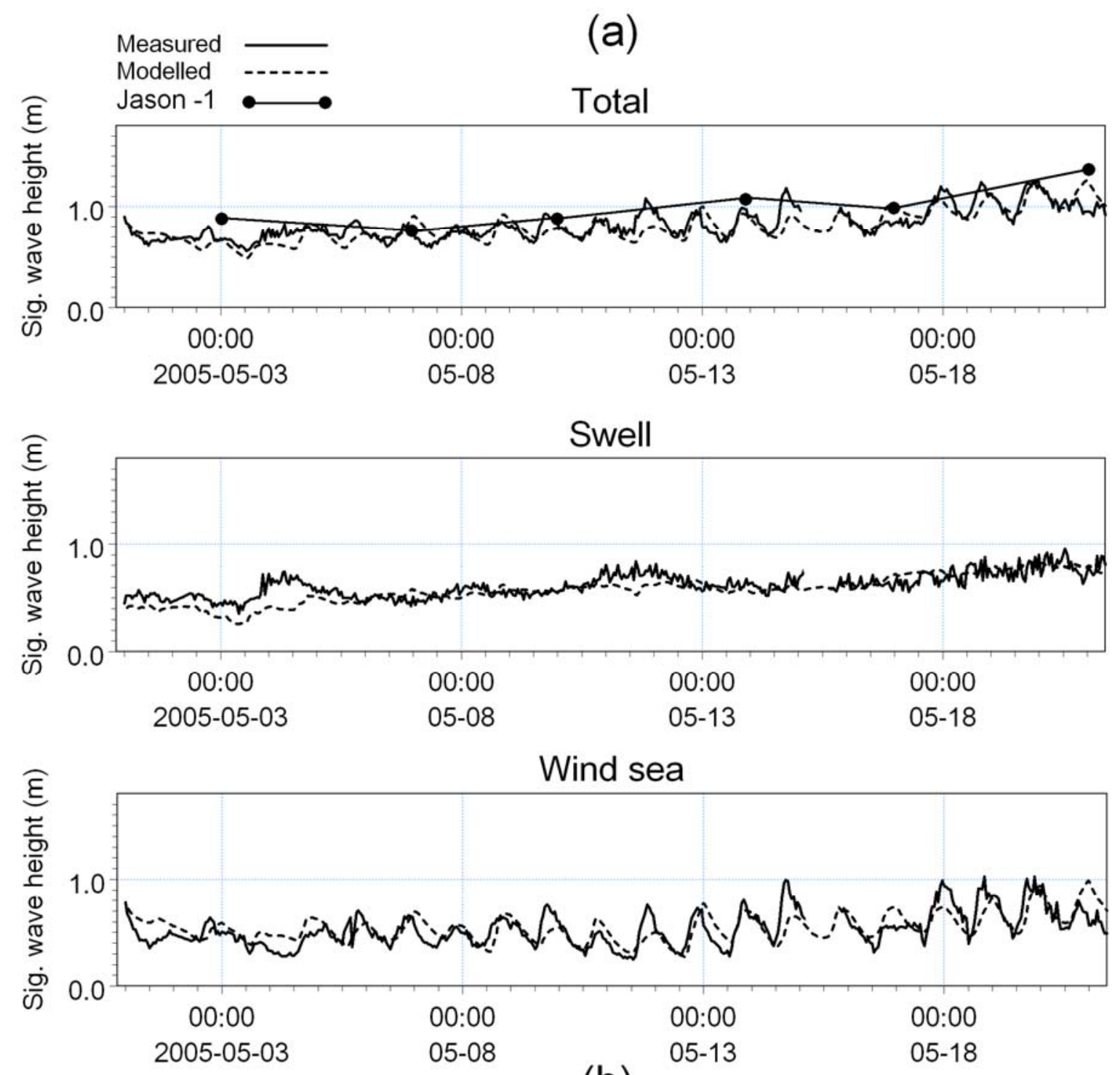

(b)
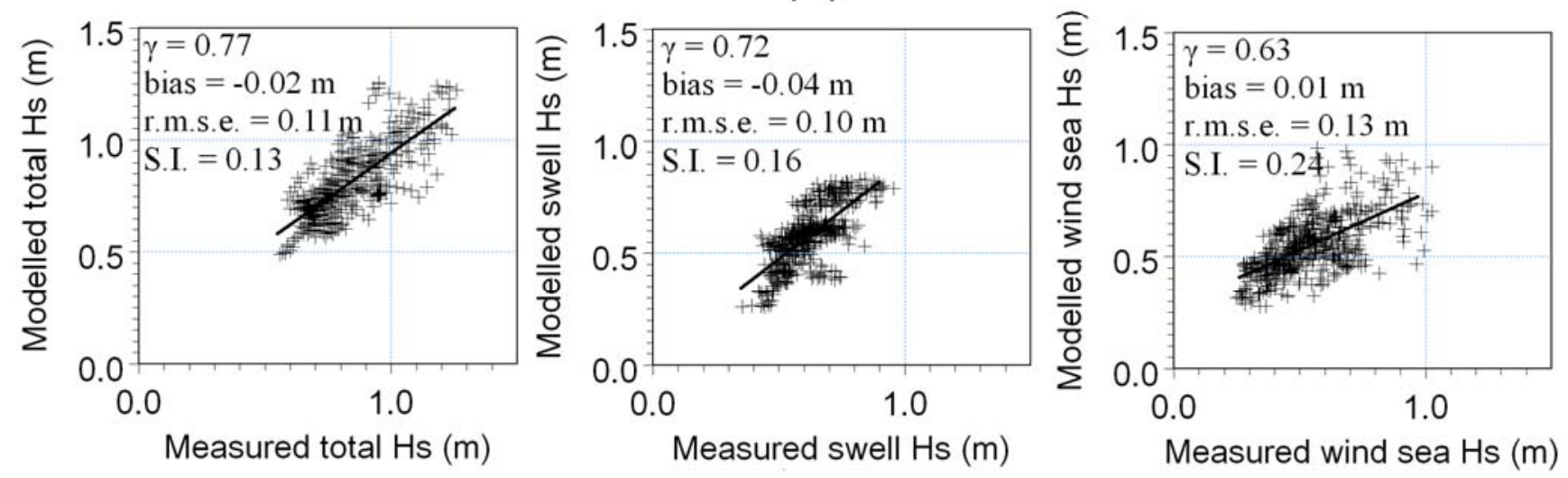

Figure 7 


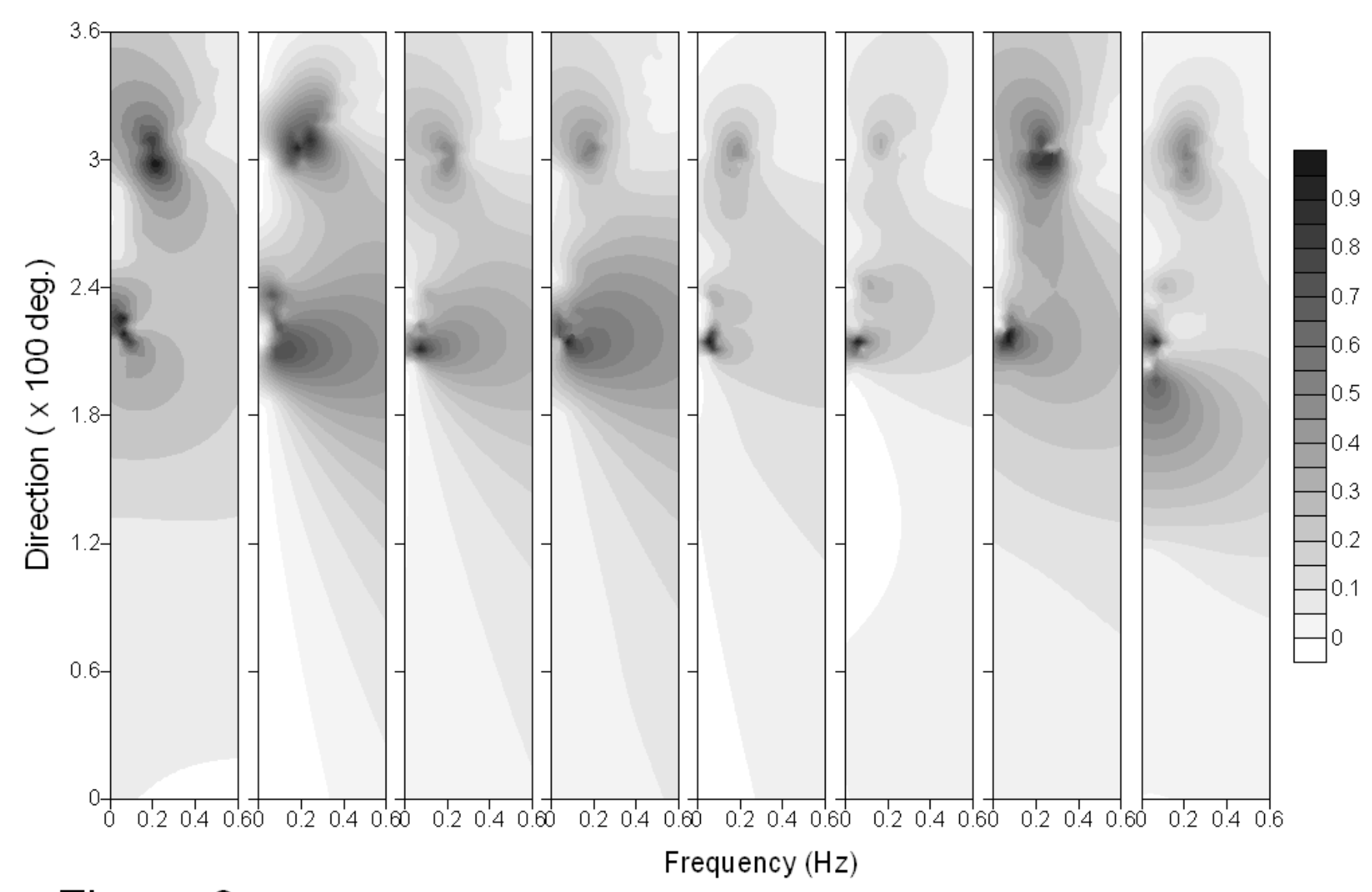

Figure 8 


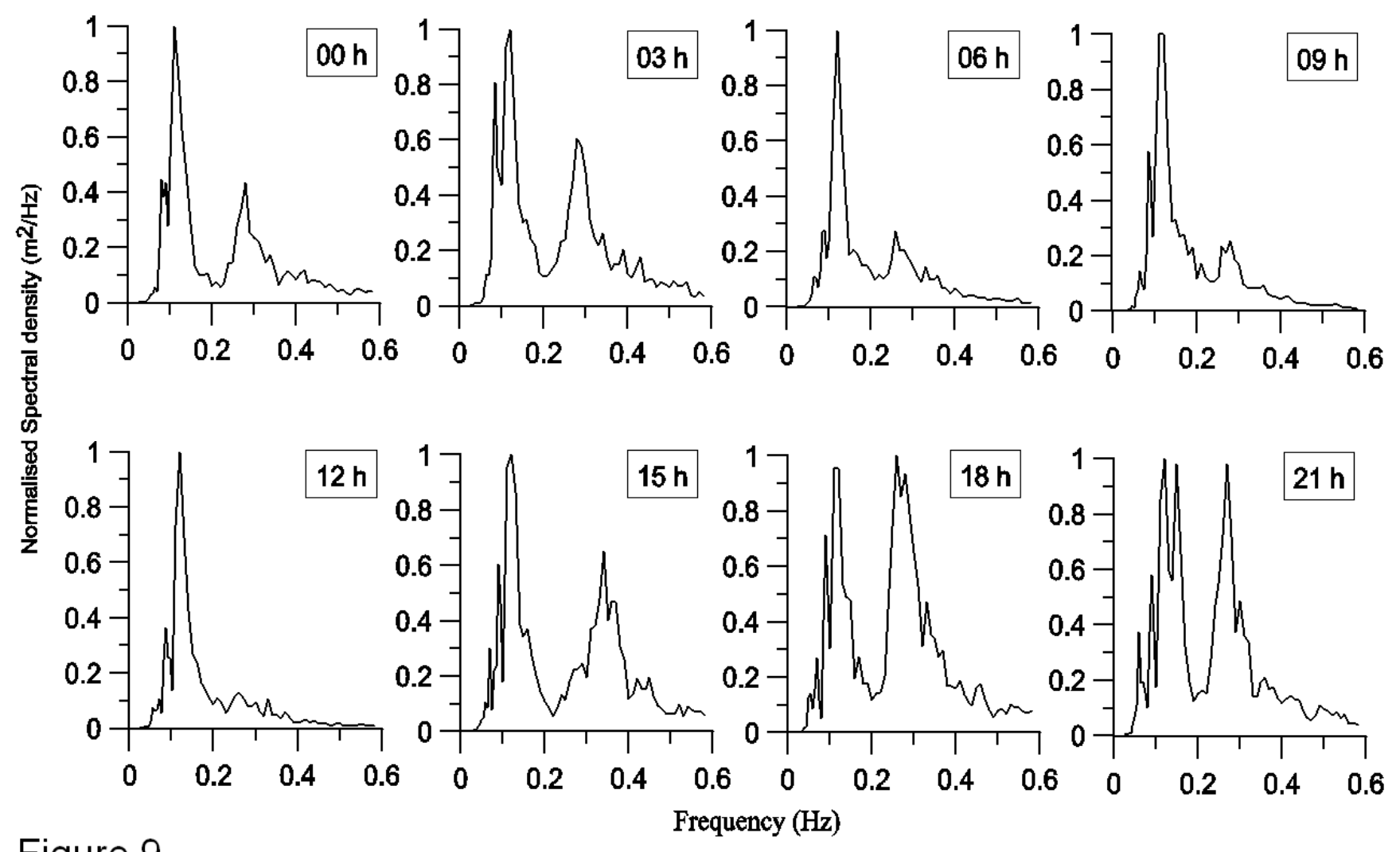

Figure 9

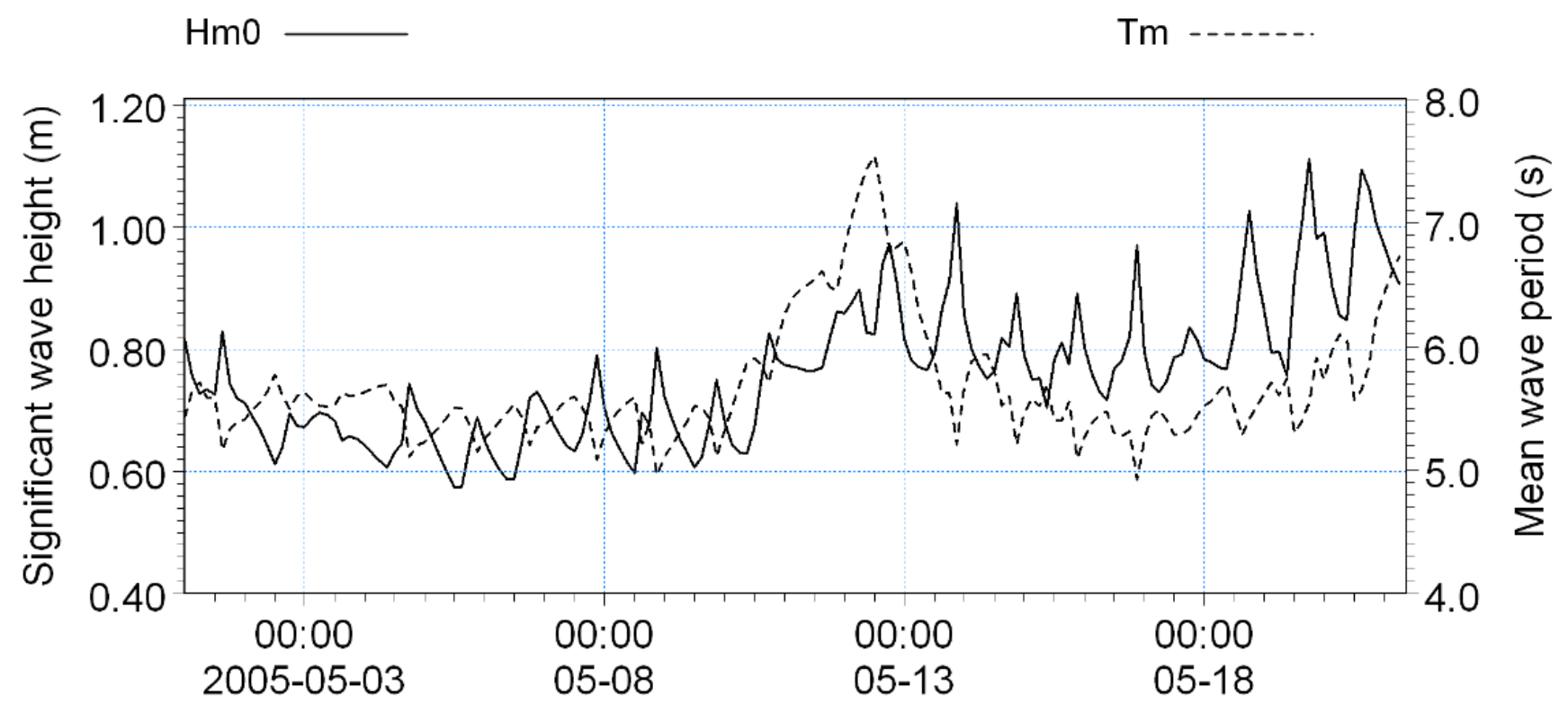

Figure 10 